\title{
A Ruptured Jejunal Arterial Aneurysm in a Young Woman Undergoing Chronic Hemodialysis Due to Myeloperoxidase-antineutrophil Cytoplasmic Antibody-associated Vasculitis
}

\begin{abstract}
Masataka Murakawa, Shigeyuki Arai, Mika Kawagoe, Yoshihiro Tomomitsu, Kohei Odajima, Masaki Ueno, Shinichiro Asakawa, Daigoro Hirohama, Michito Nagura, Osamu Yamazaki, Yoshifuru Tamura, Shunya Uchida, Shigeru Shibata and Yoshihide Fujigaki
\end{abstract}

\begin{abstract}
:
A 21-year-old woman was admitted to our hospital because of massive intestinal bleeding. She started hemodialysis due to myeloperoxidase antineutrophil cytoplasmic antibody (ANCA)-associated vasculitis (AAV) at 18 years of age. Her ANCA titers remained stable; however, her C-reactive protein increased on 5 $\mathrm{mg} / \mathrm{day}$ prednisolone before admission. Computed tomography angiography revealed a ruptured jejunal arterial aneurysm. Transcatheter arterial embolization, blood transfusion and the reinforcement of steroid therapy resolved her symptoms of AAV. Our case of a young patient with AAV and medium-sized arterial vasculitis is rare and emphasizes that the ANCA titer does not always rise, especially in patients with nonrenal vasculitis flare-ups.
\end{abstract}

Key words: aneurysm, antineutrophil cytoplasmic antibody-associated vasculitis, dialysis, flare-up, gastrointestinal bleeding, hematochezia

(Intern Med Advance Publication)

(DOI: 10.2169/internalmedicine.6721-20)

\section{Introduction}

Antineutrophil cytoplasmic antibody (ANCA)-associated vasculitis (AAV) is a systemic vasculitis involving predominantly small arteries and rarely medium arteries (1). The peak age of onset is commonly between the fifth and seventh decade of life (2). AAV is associated with ANCAs specific for myeloperoxidase (MPO) or proteinase 3 (PR3), and microscopic polyangiitis (MPA) and granulomatosis with polyangiitis (GPA) are two main types of AAV (1). ANCAs play an important role in the pathophysiology of AAV (3). The ANCA titer often rises when AAV flares up $(4,5)$. However, it has also been reported that although longitudinal ANCA measurements may be useful in patients with renal involvement, ANCAs tend to not rise in patients with nonrenal vasculitis flare-ups associated with AAV (6).
We herein report a young patient with massive intestinal bleeding caused by a ruptured jejunal arterial aneurysm, probably due to a flare-up of MPO-ANCA-positive MPA. Until the episode occurred, she had stably undergone chronic hemodialysis due to MPO-ANCA-associated glomerulonephritis, and her MPO-ANCA titer did not rise. Our case of a young patient with MPO-ANCA-positive MPA and medium-sized arterial vasculitis is rare. ANCA titers do not always rise in nonrenal vasculitis flare-ups, and a high index of suspicion for AAV is critical for a prompt diagnosis and management of vasculitis flare-ups.

\section{Case Report}

A 21-year-old Japanese woman on chronic hemodialysis (HD) visited our emergency room with complaints of nausea, abdominal pain, massive hematochezia, and dizziness. 


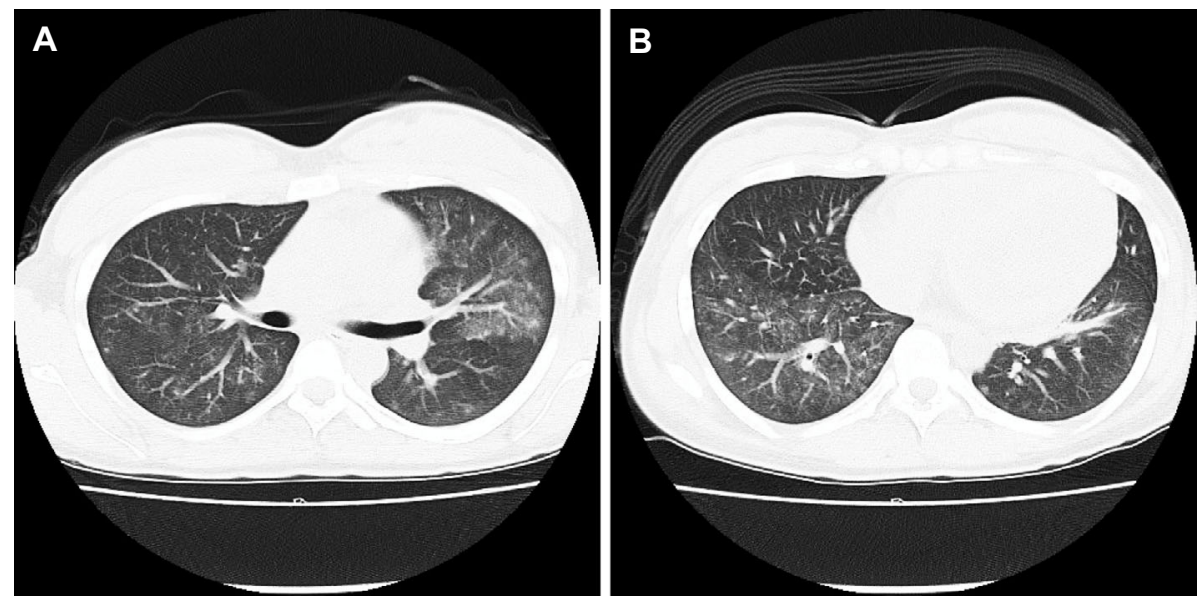

Figure 1. Computed tomography of the chest. A and B: Multiple nodules in a random pattern and patchy ground-glass opacities are found in her lungs.

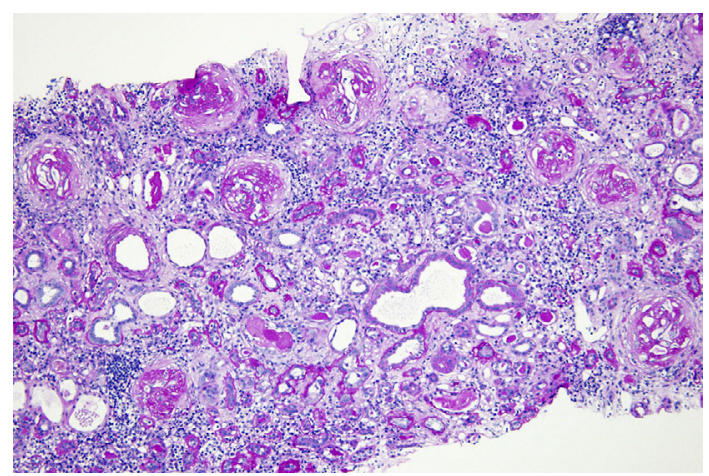

Figure 2. Light microscopic findings of a kidney biopsy. Most of the glomeruli shows global sclerosis and some glomeruli show fibrous crescents with segmental sclerosis and collapse of glomerular capillaries. Tubular atrophy, destruction of tubules and inflammatory cell infiltration in the interstitial areas are found. Periodic acid-Schiff staining. Original magnification $\times \mathbf{2 0 0}$.

She was diagnosed with ANCA-associated vasculitis at 18 years of age ( 2 years and 10 months prior to this presentation). She was referred to our hospital because of headache, dizziness, nausea, edema, reduced urine volume, severe anemia and renal failure. Physical examination on admission revealed, a body temperature of $36.0^{\circ} \mathrm{C}$, blood pressure of $141 / 83 \mathrm{mmHg}$, heart rate of $91 / \mathrm{min}$ and oxygen saturation of $98 \%$ (room air). Her body weight was $48.65 \mathrm{~kg}$ with pitting edema in her legs. Her conjunctiva was anemic and her breath sounds showed bibasilar crackles. She did not have neurological abnormalities or skin lesions. A blood analysis revealed a hemoglobin level of $3.4 \mathrm{~g} / \mathrm{dL}$, white blood cell count of $6,700 / \mu \mathrm{L}$, a platelet count of $100,000 / \mu \mathrm{L}$, an erythrocyte sedimentation rate of $83 \mathrm{~mm} /$ hour, albumin of $3.1 \mathrm{~g} /$ $\mathrm{dL}$, blood urea nitrogen of $141.0 \mathrm{mg} / \mathrm{dL}$ and creatinine of $20.73 \mathrm{mg} / \mathrm{dL}$. Immunological findings showed C-reactive protein (CRP) of $0.48 \mathrm{mg} / \mathrm{dL}$ and a negative expression of hepatitis B virus surface antigen. Autoantibodies, except for an MPO-ANCA level of $7.2 \mathrm{U} / \mathrm{mL}$, were within the normal range. Because of her anuria, she required HD. Computed tomography showed multiple nodules in a random pattern and patchy ground-glass opacities in her lungs (Fig. 1A, B) and bilateral slightly atrophic kidneys. She did not experience hemoptysis, but hemosiderin-laden macrophages were found in the bronchoalveolar lavage fluid, thus indicating alveolar hemorrhaging. A kidney biopsy revealed that most of the glomeruli showed global sclerosis, probably due to advanced crescent formation, and some glomeruli showed fibrous crescents with segmental sclerosis and collapse of glomerular capillaries (Fig. 2). Tubular atrophy, destruction of the tubules and severe inflammatory cell infiltration in interstitial tissue were found in the large areas of the cortex (Fig. 2). The interlobular arteries and arterioles did not show necrotizing angiitis. Immunofluorescence revealed peripheral lobular depositions of $\mathrm{C} 3$ and $\operatorname{IgM}$ in the sclerosing glomerulus, and electron microscopy showed discrete electron-dense deposits in the sclerotic lesions, suggesting that the depositions were nonspecific. These findings indicated the advanced phase of pauci-immune crescentic glomerulonephritis.

Polyarteritis nodosa (PAN) is defined as necrotizing arteritis of the medium or small arteries without glomerulonephritis or vasculitis in arterioles, capillaries, or venules, and not associated with ANCAs (1). Distinguishing PAN from MPA is sometimes difficult, as the clinical manifestations of both are similar and the existence of MPO-ANCA does not always rule out a diagnosis of PAN. However, our patient showed glomerulonephritis and possible pulmonary capillaritis as typical MPA manifestations. Therefore, she was diagnosed with MPA and MPO-ANCA-associated glomerulonephritis and was treated with steroid pulse therapy (500 mg methylprednisolone, daily boluses given for 3 days) and then $40 \mathrm{mg} /$ day oral prednisolone. The clinical course after introduction of corticosteroid therapy is shown in Fig. 3. She underwent chronic HD with tapering off prednisolone in 1 year without any active findings of MPA. One month after steroid withdrawal MPO-ANCA titer increased 


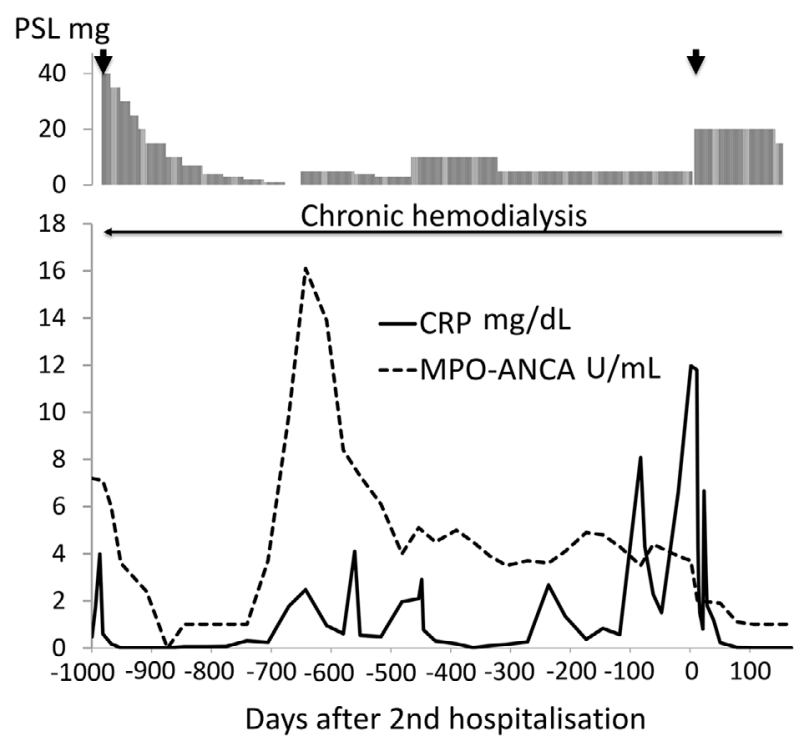

Figure 3. Clinical course after introduction of corticosteroid therapy. PSL: prednisolone, CRP: C-reactive protein, MPOANCA: myeloperoxidase-antineutrophil cytoplasmic antibody, arrows: steroid pulse therapy $(500 \mathrm{mg}$ methylprednisolone, daily boluses given for 3 days)

to $16.1 \mathrm{U} / \mathrm{L}$, but it decreased with the administration of only $5 \mathrm{mg} /$ day prednisolone. Afterwards the dose of prednisolone was increased to $10 \mathrm{mg} /$ day for fever with slight CRP elevation for fear of MPA relapse. However, we could not determine whether her MPO-ANCA titer and CRP elevation clearly reflected the disease activity.

Before the second admission, her MPO-ANCA titers remained at approximately $4 \mathrm{U} / \mathrm{L}$ (normal range $<3.4 \mathrm{U} / \mathrm{L}$ ) for one year; however, her CRP had increased over several months without dialysis complications (Fig. 3). She had undergone HD without any constitutional symptoms on $5 \mathrm{mg}$ / day prednisolone. She suddenly experienced abdominal pain and massive hematochezia and visited our emergency room on the same day. In addition to prednisolone, she was taking amlodipine besylate and telmisartan for hypertension, lanthanum carbonate hydrate for hyperphosphatemia and alfacalcidol for hypocalcemia. Physical examination showed an alert consciousness, a body temperature of $36.8^{\circ} \mathrm{C}$, blood pressure of $159 / 128 \mathrm{mmHg}$, heart rate of $107 / \mathrm{min}$ and oxygen saturation of $100 \%$ (room air). Her body weight was $45.0 \mathrm{~kg}$ without any significant weight loss. The conjunctiva was anemic. Palpation of the upper central to lower abdominal areas was painful without rebound tenderness. She did not have muscle symptoms, sensory-motor abnormalities or skin lesions. A colonoscopy examination revealed fresh blood discharge without abnormal findings. A blood analysis revealed a hemoglobin level of $5.9 \mathrm{~g} / \mathrm{dL}$, a white blood cell count of $19,700 / \mu \mathrm{L}$, a platelet count of $256,000 / \mu \mathrm{L}$, an erythrocyte sedimentation rate of $83 \mathrm{~mm} /$ hour, albumin of $2.5 \mathrm{~g} / \mathrm{dL}$, blood urea nitrogen of $40.8 \mathrm{mg} / \mathrm{dL}$ and creatinine of $8.7 \mathrm{mg} / \mathrm{dL}$. Immunological findings showed a CRP of $11.8 \mathrm{mg} / \mathrm{dL}$, normal complement 3 and 4 levels, and a nega- tive expression of hepatitis B virus surface antigen. A blood transfusion was performed. Computed tomography angiography showed multiple microaneurysms at the mesenteric arterial branches and contrast agent in the jejunum, suggesting active jejunum bleeding (Fig. 4A). A emergency arteriogram revealed multiple microaneurysms and contrast agent extravasation in the jejunum at the 2nd jejunal branch of the superior mesenteric artery (Fig. 5A, B). Transcatheter arterial embolization (TAE) of the 2nd jejunal branch of the superior mesenteric artery using n-butyl 2-cyanoacrylate (NBCA) and a lipiodol mixture successfully stopped the bleeding (Fig. 5C) and improved her abdominal symptoms. Brain magnetic resonance angiography revealed no abnormal brain vessels.

Our patient showed crescentic glomerulonephritis and pulmonary hemorrhaging at the initial presentation that indicated MPO-ANCA-positive MPA and did not have other symptoms and laboratory findings that suggested complications of polyarteritis nodosa (1). The patient was diagnosed with a ruptured jejunal arterial aneurysm due to mediumsized arterial vasculitis as a flare-up symptom of MPOANCA-positive MPA. The administration of intravenous 20 $\mathrm{mg} /$ day prednisolone sodium succinate as a tentative dose of prednisolone from the day of admission decreased the CRP level. Computed tomography angiography 8 days after TAE showed that the aneurysms disappeared (Fig. 4B). However, soon after changing from intravenous $20 \mathrm{mg} /$ day prednisolone sodium succinate to oral $5 \mathrm{mg} /$ day prednisolone, the patient developed fever, and her CRP increased again. Considering the effectiveness of intravenous $20 \mathrm{mg} /$ day prednisolone sodium succinate, steroid pulse therapy (500 mg methylprednisolone, daily boluses given for 3 days) and subsequent oral $20 \mathrm{mg} /$ day prednisolone were introduced. Her fever disappeared, and her CRP decreased again. The slightly positive MPO-ANCA titer of approximately $4 \mathrm{U} / \mathrm{L}$ before admission also decreased to a normal range (Fig. 3), suggesting that the MPO-ANCA titer might have reflected her MPA activity. A strict follow-up schedule was planned to avoid overlooking the timing of further medical treatment for AAV.

\section{Discussion}

The ruptured jejunal arterial aneurysm in our patient was considered to have been caused by rare medium-sized arterial vasculitis, which was a flare-up symptom of MPOANCA-positive MPA (1). The peak age of onset of AAV is commonly between the fifth and seventh decade of life (2). The onset of MPA in our patient was at18 years of age; however, the clinical phenotypes of adult-onset and pediatric-onset AAV are reported to be similar (7).

The incidence of gastrointestinal (GI) involvement in older reports was $5-11 \%$ in patients with GPA $(8,9)$ and 30 $56 \%$ in patients with MPA $(10,11)$. However, recently, the incidence of GI involvement in patients with AAV has been reported to be $6.5 \%$ or $7 \%$ in relatively large co- 

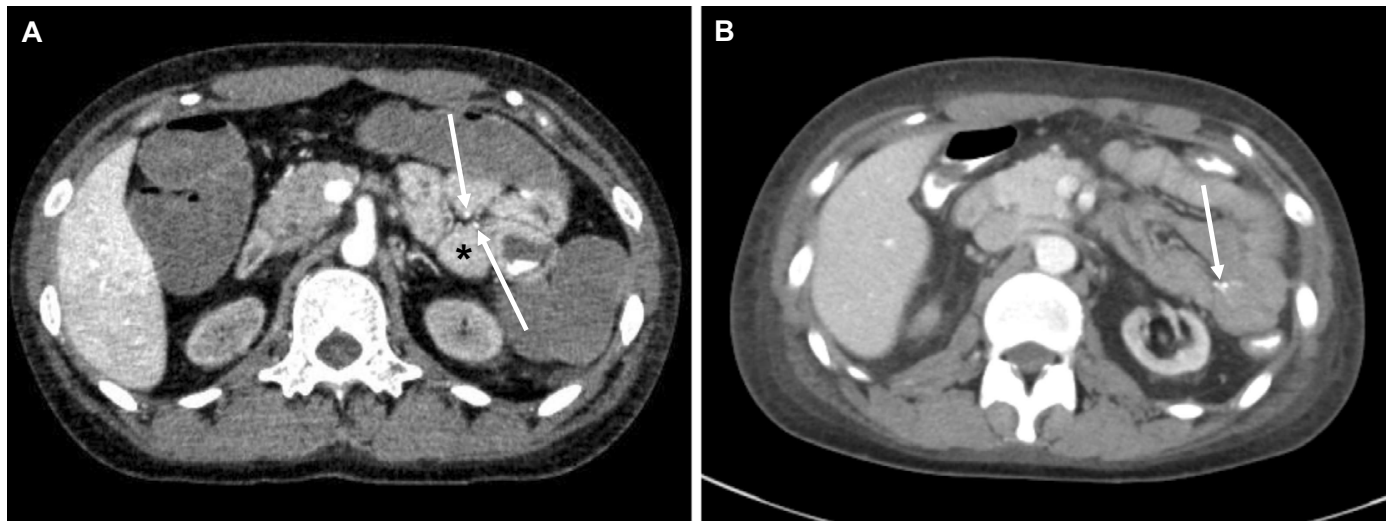

Figure 4. Computed tomography angiography in the arterial phase. A: Multiple microaneurysms at the mesenteric arterial branches (arrows) and active bleeding with contrast medium extravasation in the jejunum (asterisk) are found. B: No apparent microaneurysms at the mesenteric arterial branches are observed. Arrow shows high-density spot, indicating that n-butyl 2-cyanoacrylate (NBCA) and a lipiodol mixture is packed in the 2nd jejunal branch of the superior mesenteric artery.
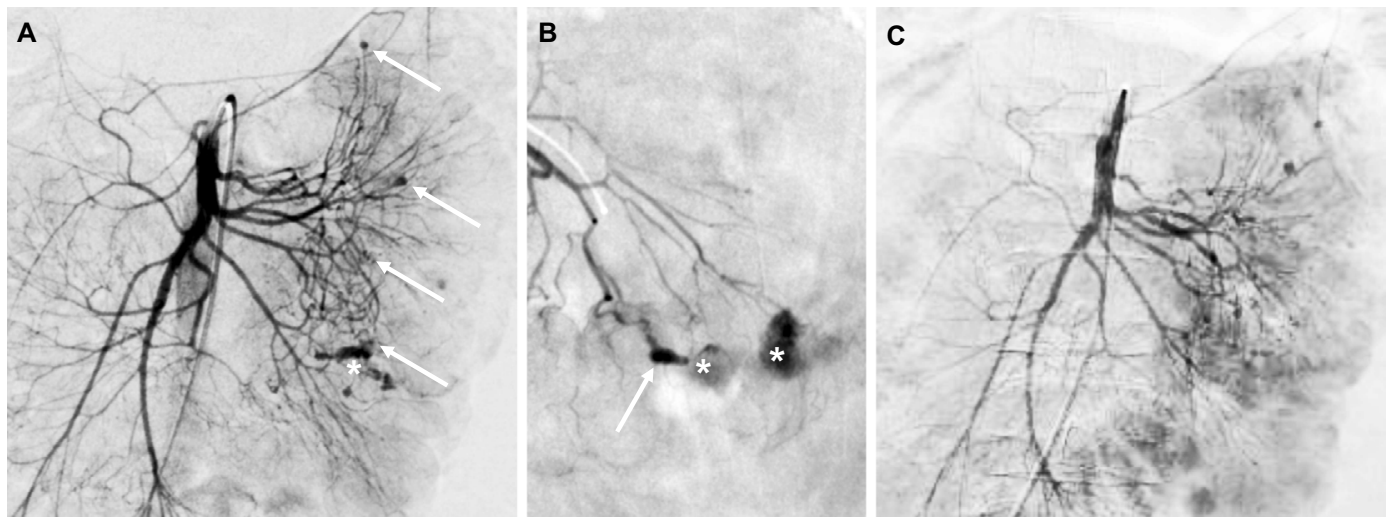

Figure 5. Digital subtraction angiography. A: Multiple microaneurysms at the mesenteric arterial branches (arrows) and contrast agent extravasation into the jejunum (asterisk). B: The jejunal artery aneurysm rapture (arrow) and contrast agent extravasation into the jejunum (asterisks). C: Active bleeding with contrast medium extravasation is not observed after transcatheter arterial embolization of the 2nd jejunal branch of the superior mesenteric artery.

horts $(12,13)$. The number of GI manifestations has been reported, and the most common GI symptoms are abdominal pain and rectal bleeding, occurring in $79 \%$ and $50 \%$ of patients, respectively (13). GI involvement in AAV may be caused by both small vessel vasculitis and rare mediumsized arterial vasculitis. Small vessel vasculitis can cause hemorrhagic ulcers or rarely ulcers with perforations. The occlusion or rupture of inflamed medium-sized arterial vasculitis with or without aneurysms may produce tissue ischemia or GI/intraperitoneal bleeding (14). As a result of tissue ischemia, ulceration, necrosis or perforation of the GI tract occurs $(1,15)$. Kirkland et al. reported 4 patients with GI bleeding among 7 MPA patients with medium vessel involvement in his hospital over a 9-year period (16). However, the ANCA data were not available. To the best of our knowledge, a total of 11 patients with AAV (3 cases of GPA (17-19) and 8 cases of MPA (13, 20-26)) presenting GI bleeding or intraabdominal bleeding due to medium- sized arteries vasculitis, which was confirmed by imaging, laparoscopy or histology of resected tissues, were reported in the literature after the first international Chapel Hill Consensus Conference on the Nomenclature of Systemic Vasculitis in 1994 (27) (Table). The medium-sized arteries involved were the left gastric artery in 4 cases, the superior mesenteric artery and its branches in 4 cases and the inferior mesenteric artery in 2 cases. The mean age was 65.2 years. Most patients showed some constitutional symptoms before GI involvement. The incidence rates of abdominal pain and GI bleeding were $27 \%$ and $36 \%$, respectively. In total, $63 \%$ of patients showed intraabdominal bleeding. All 3 patients with abdominal pain showed intraabdominal bleeding. A total of $63 \%$ of patients were proven to have arterial aneurysms. There were no patients who showed GI involvement after long-term chronic dialysis, as in our case. A surgical resection of the GI tract was performed in 4 cases. TAE with a coil was performed in 3 cases, and TAE with an un- 
Table 1. Gastrointestinal Arterial Bleeding Due to Medium-sized Arterial Vasculitis in Antineutrophil Cytoplasmic Antibodyassociated Vasculitis.

\begin{tabular}{|c|c|c|c|c|c|c|c|c|}
\hline $\begin{array}{l}\text { Case } \\
\text { No. }\end{array}$ & $\begin{array}{l}\text { Refer- } \\
\text { ences }\end{array}$ & $\begin{array}{l}\text { Reported } \\
\text { year }\end{array}$ & $\begin{array}{c}\text { Age / } \\
\text { Sex }\end{array}$ & $\begin{array}{l}\text { Phenotype/ } \\
\text { Serotype }\end{array}$ & $\begin{array}{c}\text { Constitutional } \\
\text { symptom }\end{array}$ & Organ involved & GI symptom & $\begin{array}{c}\text { Intraabdominal } \\
\text { bleeding }\end{array}$ \\
\hline 1 & 17 & 1995 & $56 / \mathrm{M}$ & GPA/C-ANCA & Yes & $\mathrm{L}, \mathrm{K}$ & Abdominal distention & Yes \\
\hline 2 & 20 & 1998 & $54 / \mathrm{M}$ & MPA/anti-MPO & No & $\mathrm{L}, \mathrm{K}$ & $\begin{array}{l}\text { Initial and 2nd: } \\
\text { massive hematochezia }\end{array}$ & No \\
\hline 3 & 21 & 2001 & $74 / \mathrm{M}$ & MPA/anti-MPO & Yes & $\mathrm{L}, \mathrm{K}$ (dialysis required) & Massive melena & No \\
\hline 4 & 18 & 2004 & $78 / \mathrm{F}$ & aGPA/anti-MPO & Yes & $\begin{array}{l}\text { Liver, Spleen, K, gallbladder, } \\
\text { pancreas, ovaries, uterus, } \\
\text { adrenal glands, mesentery, } \\
\text { sternum }\end{array}$ & No & Yes \\
\hline 5 & 22 & 2004 & $69 / \mathrm{M}$ & MPA/anti-MPO & Yes & $\mathrm{K}$ & $\begin{array}{l}\text { Severe generalized } \\
\text { abdominal pain }\end{array}$ & Yes \\
\hline 6 & 19 & 2004 & $58 / \mathrm{F}$ & aGPA/anti-PR3 & Yes & Skin, K & $\begin{array}{l}\text { Initial: Bloody bowel } \\
\text { movements }\end{array}$ & $\begin{array}{l}\text { Initial: No } \\
\text { 2nd: Yes }\end{array}$ \\
\hline 7 & 23 & 2009 & $70 / \mathrm{F}$ & MPA/anti-MPO & Yes & $\begin{array}{l}\mathrm{K} \text {, heart, pancreas adrenal } \\
\text { gland, bladder }\end{array}$ & No & Yes \\
\hline 9 & 25 & 2013 & $56 / \mathrm{M}$ & MPA/anti-MPO & Yes & $\mathrm{L}, \mathrm{K}$ (dialysis required) & $\begin{array}{l}\text { Initial: melena, 2nd: } \\
\text { hematochezia }\end{array}$ & No \\
\hline 10 & 26 & 2017 & $74 / \mathrm{M}$ & MPA/anti-MPO & Yes & $\mathrm{K}$ & Abdominal pain & Yes \\
\hline 11 & 13 & 2018 & $55 / \mathrm{M}$ & MPA/anti-MPO & ND & $\begin{array}{c}\text { Skin, joint, eye, ENT, L, K, } \\
\text { prostate }\end{array}$ & Abdominal pain & Yes \\
\hline $\begin{array}{l}\text { Our } \\
\text { case }\end{array}$ & & & $21 / \mathrm{F}$ & MPA/anti-MPO & No & $\mathrm{K}$ (on dialysis), $\mathrm{L}$ & $\begin{array}{l}\text { Abdominal pain, } \\
\text { massive melena }\end{array}$ & No \\
\hline
\end{tabular}

GI: gastrointestinal, GPA: granulomaouts polyangiitis, aGPA: atypical granulomaouts polyangiitis, MPA: microscopic polyangiitis, C-ANCA: cytoplasmic antineutrophil cytoplasmic antibody (ANCA), anti-MPO: anti-myeloperoxidase ANCA, anti-PR3: anti-protease 3 ANCA, ND: not described, L: lung, K: kidney, ENT: ear, nose and throat, SMA: superior mesenteric artery, IMA: inferior mesenteric artery, BT: blood transfusion, TAE: transcatheter arterial embolization, CYC: cyclophosphamide, PE: plasma exchange, IVIgG: intravenous immunoglobulin, NBCA: n-butyl 2-cyanoacrylate

\begin{tabular}{|c|c|c|c|c|c|c|}
\hline \multicolumn{7}{|c|}{ Continued } \\
\hline $\begin{array}{l}\text { Case } \\
\text { No. }\end{array}$ & $\begin{array}{l}\text { Medium-sized } \\
\text { artery involved }\end{array}$ & Angiography & Laparotomy & $\begin{array}{c}\text { Treatment after GI } \\
\text { involvement }\end{array}$ & Autopsy & Outcome \\
\hline 1 & $\begin{array}{l}\text { Left gastric artery } \\
\text { (a.) }\end{array}$ & & & $\begin{array}{l}\text { Cardiopulmonary } \\
\text { resuscitation }\end{array}$ & $\begin{array}{l}\text { Ruptured a. with } \\
\text { aneurysm }\end{array}$ & $\begin{array}{c}\text { Died (hemorrhagic } \\
\text { shock) }\end{array}$ \\
\hline 2 & Branch of ileal a. & $\begin{array}{l}\text { Bleeding from a } \\
\text { branch of lleal a. }\end{array}$ & & $\begin{array}{l}\text { Initial: BT, TAE, } \\
\text { steroid 2nd: ileotomy }\end{array}$ & & Alive \\
\hline 3 & Branch of ileal a. & $\begin{array}{l}\text { Bleeding from a } \\
\text { branch of lleal a. }\end{array}$ & & $\begin{array}{l}\text { TAE (coil), steroid, } \\
\text { CYC }\end{array}$ & No & $\begin{array}{l}\text { Died (pulmonary } \\
\text { hemorrhage) }\end{array}$ \\
\hline 4 & Gastric subserosa & & & BT, steroid & $\begin{array}{l}\text { Ruptured } \\
\text { aneurysm in the } \\
\text { gastric subserosa }\end{array}$ & $\begin{array}{c}\text { Died (hemorrhagic } \\
\text { shock) }\end{array}$ \\
\hline 5 & $\begin{array}{c}\text { Initial: } \\
\text { gastroduodenal a. } \\
\text { 2nd: gastroepiploic } \\
\text { vessels } \\
\text { 3nd:splenic a. }\end{array}$ & $\begin{array}{l}\text { 2nd: bleeding from } \\
\text { gastroepiploic } \\
\text { vessels 3rd: leaking } \\
\text { aneurysm in the } \\
\text { splenic a. }\end{array}$ & $\begin{array}{l}\text { Initial: bleeding vessels in } \\
\text { the supracolic compartment, } \\
\text { abnormal, enlarged } \\
\text { mesenteric circulation } \\
\text { 2nd: bleeding form } \\
\text { gastroepiploic vessels }\end{array}$ & $\begin{array}{c}\text { Initial and 2nd: ligation } \\
\text { of artery, BT, steroid, } \\
\text { CYC } \\
\text { 3rd: pancreatectomy, } \\
\text { splenectomy, infliximab }\end{array}$ & No & $\begin{array}{l}\text { Died (catheter- } \\
\text { related sepsis, } \\
\text { respiratory tract } \\
\quad \text { infection) }\end{array}$ \\
\hline 6 & $\begin{array}{l}\text { Initial: middle } \\
\text { colic a. } \\
\text { 2nd: SMA }\end{array}$ & $\begin{array}{l}\text { 2nd: rupture of } \\
\text { multiple superior } \\
\text { mesenteric } \\
\text { aneurysms }\end{array}$ & $\begin{array}{l}\text { Initial: ruptured middle } \\
\text { colic a. }\end{array}$ & $\begin{array}{l}\text { Initial: small bowel } \\
\text { removal, splenectomy, } \\
\text { appendectomy, steroid, } \\
\text { PE, CYC, BT } \\
\text { 2nd: colectomy, blood } \\
\text { transfusion, PE }\end{array}$ & No & $\begin{array}{c}\text { Died (hemorrhagic } \\
\text { shock) }\end{array}$ \\
\hline 7 & Left gastric a. & & & Steroid & $\begin{array}{l}\text { Ruptured left } \\
\text { gastric a. }\end{array}$ & $\begin{array}{c}\text { Died (hemorrhagic } \\
\text { shock) }\end{array}$ \\
\hline 8 & $\begin{array}{l}\text { Branch of the left } \\
\text { gastric a. }\end{array}$ & & & Steroid & $\begin{array}{l}\text { Rupture of branch } \\
\text { of the left gastric } \\
\text { pseudoaneurysm }\end{array}$ & $\begin{array}{c}\text { Died (hemorrhagic } \\
\text { shock) }\end{array}$ \\
\hline 9 & $\begin{array}{l}\text { Initial: a branch of } \\
\text { IMA } \\
\text { 2nd: a branch of } \\
\text { IMA }\end{array}$ & $\begin{array}{l}\text { Initial: bleeding from } \\
\text { a branch of IMA } \\
\text { 2nd: bleeding from a } \\
\text { branch of IMA }\end{array}$ & & $\begin{array}{c}\text { Initial: TAE (steel coil), } \\
\text { steroid 2nd: TAE (steel } \\
\text { coil), BT, steroid, CYC, } \\
\text { PE, IVIgG }\end{array}$ & & Alive \\
\hline 10 & Left gastric a. & & $\begin{array}{c}\text { Ruptured left gastric a. } \\
\text { aneurysm }\end{array}$ & $\begin{array}{c}\text { Steroid, CYC, } \\
\text { gastrectomy }\end{array}$ & No & $\begin{array}{c}\text { Died (hemorrhagic } \\
\text { shock) }\end{array}$ \\
\hline $\begin{array}{l}\text { Our } \\
\text { case }\end{array}$ & $\begin{array}{l}\text { Branch of jejunal } \\
\text { a. }\end{array}$ & $\begin{array}{c}\text { Bleeding from } \\
\text { aneurysms in a } \\
\text { branch of jejunal a. }\end{array}$ & & $\begin{array}{l}\text { Steroid, BT, TAE } \\
\text { (NBCA) }\end{array}$ & & Alive \\
\hline
\end{tabular}


known material was performed in 1 case; these procedures successfully stopped the arterial bleeding. Eight patients died and, as for the breakdown of causes of death, 1 death was caused by hemorrhagic shock due to GI bleeding, 5 were caused by hemorrhagic shock due to intraperitoneal bleeding, 1 was caused by pulmonary hemorrhaging and 1 was caused by sepsis. The diagnosis and treatment of GI middle-sized arterial vasculitis with bleeding may be difficult and relies mostly on imaging. Our patient received TAE with NBCA. TAE with NBCA, which enables the occlusion of collateral vessels connected to the bleeding focus, should be considered a safe, efficient method for the treatment of GI bleeding (28).

Experimental and clinical data have provided evidence that ANCAs are not only biomarkers of AAV but they also play an important role in its pathogenesis (29). However, ANCAs may not be the only factor for disease activation because increases in ANCAs are not often followed by relapse (30-32). On the other hand, serial measurements of PR 3- and MPO-ANCA titers in patients with AAV during remission can help predict relapses, and preemptive increases in immunosuppression treatment following fourfold titer rises reduce the risk of relapse (4). Moreover, adjustments to immunosuppression therapy based on smaller titer changes appear to result in favorable outcomes (4). Recently, it was reported that an increase in ANCAs is strongly related to a relapse in patients with renal involvement, whereas an increase in ANCAs is only weakly associated with a relapse in patients with nonrenal disease (6). More recently, this was confirmed in Japanese hemodialysis patients with ANCAassociated glomerulonephritis (33). Although the pathogenesis is not known, the ANCA titer did not rise at the time of the MPO-AAV flare-up in our dialysis patient. Throughout her clinical course though within the low titer, MPO-ANCA titer was normalized by high dose corticosteroids, and the CRP level seemed to be reduced by the increased dose of corticosteroids, suggesting that the elevation of CRP titer associated with a low MPO-ANCA titer might reflect the AAV activity in our patient.

Several investigators found that the relapse rates are lower if steroid treatment is continued long term (34-36). In a cohort in Japan, a prednisolone dose of $\leq 2.5 \mathrm{mg} /$ day at 24 months after the initiation of remission induction therapy was associated with later relapse (37). Moreover, the use of steroid therapy for longer than 6 months is reported to be associated with a significantly increased risk of infection but not a significant reduction in the risk of relapse (38). On the other hand, it has been reported that the relapse rate was significantly lower after initiating chronic dialysis than before initiating chronic dialysis $(33,39-41)$. Considering the older age of patients with AAV receiving chronic dialysis in Japan, Miyabe et al. recommended that the early tapering of steroids should be considered to avoid death rather than focusing only on relapse (33). These recommendations might not be adaptable to our young dialysis patient taking $5 \mathrm{mg}$ / day prednisolone at the time of relapse 34 months after the initiation of remission induction therapy. However, given the side effect that are associated with lengthy and high-dose use of corticosteroids, there is a need for other effective and safe therapies. Although there is still not enough evidence in patients undergoing $\mathrm{HD}$, we need to consider treatments with a combination of low-dose corticosteroids and either azathioprine, rituximab, methotrexate or mycophenolate mofetil based on the JCS 2017 Guidelines on Management of Vasculitis Syndrome recommendation for remissionmaintenance of MPA in our patient (42).

In summary, it is difficult to predict a flare-up of AAV. When dialysis patients with AAV show elevated CRP levels without a significant rise in ANCAs, we need to rule out dialysis complications, and a high index of suspicion for AAV is critical for the prompt diagnosis and timely management of vasculitis flare-ups. When patients show sudden GI symptoms with bleeding, imaging of medium-sized arteries and TAE should therefore be considered.

The authors state that they have no Conflict of Interest (COI).

\section{References}

1. Jennette JC, Falk RJ, Bacon PA, et al. 2012 revised International Chapel Hill Consensus Conference Nomenclature of Vasculitides. Arthritis Rheum 65: 1-11, 2013.

2. Kamesh L, Harper L, Savage CO. ANCA-positive vasculitis. J Am Soc Nephrol 13: 1953-1960, 2002.

3. Wilde B, van Paassen P, Witzke O, Tervaert JWC. New pathophysiological insights and treatment of ANCA-associated vasculitis. Kidney Int 79: 599-612, 2011

4. Han WK, Choi HK, Roth RM, McCluskey RT, Niles JL. Serial ANCA titers: useful tool for prevention of relapses in ANCAassociated vasculitis. Kidney Int 63: 1079-1085, 2003.

5. Yamaguchi M, Ando M, Kato S, et al. Increase of Antimyeloperoxidase Antineutrophil Cytoplasmic Antibody (ANCA) in Patients with Renal ANCA-associated Vasculitis: Association with Risk to Relapse. J Rheumatol 42: 1853-1860, 2015.

6. Kemna MJ, Damoiseaux J, Austen J, et al. ANCA as a predictor of relapse: useful in patients with renal involvement but not in patients with nonrenal disease. J Am Soc Nephrol 26: 537-542, 2015.

7. Calatroni M, Oliva E, Gianfreda D, et al. ANCA-associated vasculitis in childhood: recent advances. Ital J Pediatr 43: 46, 2017.

8. Haworth SJ, Pusey CD. Severe intestinal involvement in Wegener's granulomatosis. Gut 25: 1296-1300, 1984.

9. Srinivasan U, Coughlan RJ. Small intestinal perforation complicating Wegener's granulomatosis. Rheumatology (Oxford) 38: 289290, 1999.

10. Gayraud M, Guillevin L, le Toumelin P, et al.; French Vasculitis Study Group. Long-term followup of polyarteritis nodosa, microscopic polyangiitis, and Churg-Strauss syndrome: analysis of four prospective trials including 278 patients. Arthritis Rheum 44: 666$675,2001$.

11. Lhote F, Cohen P, Guillevin L. Polyarteritis nodosa, microscopic polyangiitis and Churg-Strauss syndrome. Lupus 7: 238-258, 1998.

12. Mahr A, Katsahian $S$, Varet $H$, et al.; French Vasculitis Study Group (FVSG) and the European Vasculitis Society (EUVAS. Revisiting the classification of clinical phenotypes of anti-neutrophil cytoplasmic antibody-associated vasculitis: a cluster analysis. Ann Rheum Dis 72: 1003-1010, 2013. 
13. Eriksson P, Segelmark M, Hallböök O. Frequency, Diagnosis, Treatment, and Outcome of Gastrointestinal Disease in Granulomatosis with Polyangiitis and Microscopic Polyangiitis. J Rheumatol 45: 529-537, 2018.

14. De Virgilio A, Greco A, Magliulo G, et al. Polyarteritis nodosa: A contemporary overview. Autoimmun Rev 15: 564-570, 2016.

15. Bagai S, Sharma A, Gupta R, et al. Gastrointestinal Involvement in Granulomatosis with Polyangiitis: Case Report and Review. Indian J Nephrol 29: 415-418, 2019.

16. Kirkland GS, Savige J, Wilson D, Heale W, Sinclair RA, Hope RN. Classical polyarteritis nodosa and microscopic polyarteritis with medium vessel involvement--a comparison of the clinical and laboratory features. Clin Nephrol 47: 176-180, 1997.

17. Aoki N, Soma K, Owada T, Ishii H. Wegener's granulomatosis complicated by arterial aneurysm. Intern Med 34: 790-793, 1995.

18. Kurata A, Nishimura $Y$, Yamato $T$, et al. Systemic granulomatous necrotizing vasculitis in a MPO-ANCA-positive patient. Pathol Int 54: 636-640, 2004.

19. Dutton-Gaddis JG, Oyekan TB, Haraway GD, Crapse FJ. Middle colic artery rupture in a patient with ANCA associated vasculitis: a case report. J Okla State Med Assoc 97: 364-366, 2004.

20. Inaguma $D$, Kurata $K$, Ishihara $S$, Machida $H$, Yaomura $T$, Kumon S. [A case of MPO-ANCA-related vasculitis that recurred as gastrointestinal bleeding and presented difficulty in treatment]. Nihon Jinzo Gakkai Shi 40: 560-565, 1998 (in Japanese).

21. Ueda S, Matsumoto $M$, Ahn $T$, et al. Microscopic polyangiitis complicated with massive intestinal bleeding. J Gastroenterol 36: 264-270, 2001.

22. Ravanan R, Weale AR, Lear PA, Thornton MJ, Kamel D, Tomson CR. Hemoperitoneum in a patient with ANCA-associated polyangiitis syndrome. Am J Kidney Dis 44: 908-911, 2004.

23. Yahata $\mathrm{K}$, Okamoto $\mathrm{C}$, Imamaki $\mathrm{H}$, et al. Fatal hemoperitoneum due to rupture of the left gastric artery in a patient with microscopic polyangiitis. Clin Exp Nephrol 13: 512-517, 2009.

24. Ito Y, Tanaka A, Sugiura Y, Sezaki R. An autopsy case of intraabdominal hemorrhage in microscopic polyangiitis. Intern Med $\mathbf{5 0}$ 1501-1502, 2011.

25. Li L, Li X, Fu P, Liu F. Recurrent gastrointestinal bleeding with ANCA associated glomerulonephritis successfully treated by transarterial embolization. Pak J Med Sci 29: 1465-1467, 2013.

26. Muray Cases S, Andreu Muñoz A, Cabezuelo Romero JB. Glomerulonephritis secondary to a microscopic polyangiitis complicated by rupture of a left gastric artery aneurysm. Med Clin (Barc) 148: 383-384, 2017.

27. Jennette JC, Falk RJ, Andrassy K, et al. Nomenclature of systemic vasculitides. Proposal of an international consensus conference. Arthritis Rheum 37: 187-192, 1994.

28. Kim PH, Tsauo J, Shin JH, Yun SC. Transcatheter Arterial Embolization of Gastrointestinal Bleeding with N-Butyl Cyanoacrylate: A Systematic Review and Meta-Analysis of Safety and Efficacy. J Vasc Interv Radiol 28: 522-531, 2017.

29. Geetha D, Jefferson JA. ANCA-Associated Vasculitis: Core Curriculum 2020. Am J Kidney Dis 75: 124-137, 2020.

30. Tervaert JW, van der Woude FJ, Fauci AS, et al. Association between active Wegener's granulomatosis and anticytoplasmic anti- bodies. Arch Intern Med 149: 2461-2465, 1989.

31. Boomsma MM, Stegeman CA, van der Leij MJ, et al. Prediction of relapses in Wegener's granulomatosis by measurement of antineutrophil cytoplasmic antibody levels: a prospective study. Arthritis Rheum 43: 2025-2033, 2000.

32. Thai LH, Charles P, Resche-Rigon M, Desseaux K, Guillevin L. Are anti- proteinase-3 ANCA a useful marker of granulomatosis with polyangiitis (Wegener's) relapses? Results of a retrospective study on 126 patients. Autoimmun Rev 13: 313-318, 2014.

33. Miyabe Y, Karasawa K, Takabe T, et al. Long-term follow-up characteristics of patients with anti-neutrophil cytoplasmic antibody (ANCA)-associated vasculitis (AAV) receiving chronic hemodialysis at a single center. Clin Exp Nephrol 24: 136-142, 2020.

34. Walsh M, Merkel PA, Mahr A, Jayne D. Effects of duration of glucocorticoid therapy on relapse rate in antineutrophil cytoplasmic antibody-associated vasculitis: A meta-analysis. Arthritis Care Res (Hoboken) 62: 1166-1173, 2010.

35. Wada T, Hara A, Arimura Y, Sada KE, Makino H. Research Group of Intractable Vasculitis, Ministry of Health, Labor, and Welfare of Japan. Risk factors associated with relapse in Japanese patients with microscopic polyangiitis. J Rheumatol 39: 545-551, 2012.

36. Walsh M, Flossmann O, Berden A, et al. European Vasculitis Study Group. Risk factors for relapse of antineutrophil cytoplasmic antibody-associated vasculitis. Arthritis Rheum 64: 542-548, 2012.

37. Hara A, Wada T, Sada KE, et al. Research Committee on Intractable Vasculitides, and the Strategic Study Group to Establish the Evidence for Intractable Vasculitis Guideline. Risk Factors for Relapse of Antineutrophil Cytoplasmic Antibody-associated Vasculitis in Japan: A Nationwide, Prospective Cohort Study. J Rheumatol 45: 521-528, 2018.

38. McGregor JG, Hogan SL, Hu Y, Jennette CE, Falk RJ, Nachman $\mathrm{PH}$. Glucocorticoids and relapse and infection rates in antineutrophil cytoplasmic antibody disease. Clin J Am Soc Nephrol 7: 240-247, 2012.

39. Watts R, Lane S, Hanslik T, et al. Development and validation of a consensus methodology for the classification of the ANCAassociated vasculitides and polyarteritis nodosa for epidemiological studies. Ann Rheum Dis 66: 222-227, 2007.

40. Lionaki S, Hogan SL, Jennette CE, et al. The clinical course of ANCA small-vessel vasculitis on chronic dialysis. Kidney Int 76: 644-651, 2009.

41. Moiseev S, Novikov P, Jayne D, Mukhin N. End-stage renal disease in ANCA- associated vasculitis. Nephrol Dial Transplant 32: 248-253, 2017.

42. Isobe M, Amano K, Arimura Y, et al. JCS Joint Working Group. JCS 2017 Guideline on Management of Vasculitis Syndrome - Digest Version. Circ J 84: 299-359, 2020.

The Internal Medicine is an Open Access journal distributed under the Creative Commons Attribution-NonCommercial-NoDerivatives 4.0 International License. To view the details of this license, please visit (https://creativecommons.org/licenses/ by-nc-nd/4.0/).

\section{(C) The Japanese Society of Internal Medicine Intern Med Advance Publication}

